\title{
GIÁ TRI VỐN HÓA THỊ TRƯờNG CHÚNG KHOÁN VÀ TĂNG TRƯởNG KINH TẾ TẠI ASEAN6
}

\author{
LẠI CAO MAI PHU'ONG \\ Truờng Đại học Công nghiệp thành phố Hồ Chí Minh; \\ lcmphuong@gmail.com
}

Tóm tắt. Mục tiêu của bài viết là nghiên cứu khái quát thị trường chứng khoán (TTCK) ASEAN trước thời điểm cộng đồng kinh tế ASEAN (AEC) được thành lập vào cuối năm 2015, đồng thời, lượng hóa tác động của giá trị vốn hóa TTCK đến tăng trưởng kinh tế tại sáu quốc gia trong ASEAN gồm Thái Lan, Singapore, Phillipine, Indonesia, Malaysia, và Việt Nam (ASEAN6).Trong phần nghiên cứu định lượng, bài viết sử dụng dữ liệu bảng theo phương pháp ước lượng bình phương nhỏ nhất tổng quát (General Least Square: GLS) để kiểm tra tác động của quy mô thị trường chứng khoán (TTCK) đến tăng trưởng kinh tế tại các quốc gia trong ASEAN6. Dư liệu được thu thập từ Ngân hàng thế giới trong giai đoạn 2000- 2014. Nghiên cứu sử dụng biến phụ thuộc là tốc độ tăng trưởng tổng sản phẩm quốc nội- đại diện cho tốc độ tăng trưởng kinh tế hàng năm, biến độc lập đại diện cho quy mô phát triển của TTCK được tính bằng cách lấy giá trị vốn hóa TTCK so với giá trị tổng sản phẩm quốc nội, ngoài ra, các biến kiểm soát khác được sử dụng trong mô hình gồm chi tiêu chính phủ và độ mở thương mại. Kết quả cho thấy cả ba biến đều có tác động tích cực đến tăng trưởng kinh tế tại ASEAN6. Kết quả nghiên cứu có giá trị đối với các nhà quản lý trong việc cung cấp một số gợi ý nhằm phát triển TTCK bền vững, góp phần thúc đẩy tăng trưởng kinh tế tại các quốc gia này.

Từ khóa. Giá trị vốn hóa, thị trường chứng khoán, ASEAN, tăng trưởng kinh tế

\section{STOCK MARKET CAPITALIZATION AND ECONOMIC GROWTH IN ASEAN6}

\begin{abstract}
The objective of this article is to study overview the ASEAN stock market before the ASEAN Economic Community (AEC) was established by the end of 2015 and quantify the impact of the stock market capitalization to economic growth in six ASEAN countries including Thailand, Singapore, Philippines, Indonesia, Malaysia, and Vietnam (ASEAN6). In the quantitative study, General Least Square (GLS) to test the impact of stock market size on economic growth in ASEAN6 countries. Data collected from the World Bank during the period 2000-2014. The research using the dependent variable is the growth rate of gross domestic product - representing the annual economic growth rate, independent variable representing the scale of development of the stock market is calculated by taking the stock market capitalization value per the gross domestic product value; in addition, other control variables used in the model include government expenditure and level open trade. The results show that all three variables have a positive impact on economic growth in ASEAN6. Research results are valuable for managers in providing some suggestions for developing sustainable stock markets, contributing to economic growth in these countries.
\end{abstract}

Keywords. Capitalization, stock market, ASEAN, economic growth

\section{1 ĐặT VẤN ĐỀ}

Lý thuyết tài chính cho rằng thị trường chứng khoán (TTCK) là kênh huy động vốn trung và dài hạn, kết nối giữa nhu cầu huy động vốn dài hạn với nhu cầu đầu tư dài hạn, là nơi cung cấp các cơ hội đầu tư khác nhau cho công chúng, đánh giá giá trị doanh nghiệp và tình hình của nền kinh tế, cũng là nơi hội nhập quốc tế và thực thi các chính sách phát triển của nhà nước và chính phủ. Chẳng hạn, lý thuyết của Harrod (1939), Domar (1946), Solow (1956), Lucas (1988) cho rằng mở rộng đầu tư sẽ có tác động đến tăng trưởng kinh tế. Tuy nhiên, kết quả nghiên cứu thực nghiệm về tác động của sự phát triển tài chính nói riêng và thị trường chứng khoán (TTCK) nói chung đến tăng trưởng kinh tế đưa ra nhiều kết quả không đồng nhất. Trong khi, kết quả nghiên cứu của Patrick (1966), Mian và cộng sự (2010), Kolapo và cộng sự (2012) cho thấy sự phát triển của TTCK có tác động tích cực đến tăng trưởng kinh tế, thì nghiên 
cứu của Nyong (1997) cho thấy sự tác động này là tiêu cực, và nghiên cứu của Levine và Zervos (1998) không tìm thấy mối liên quan giữa sự phát triển TTCK và tăng trưởng kinh tế. Thực tế, ở những giai đoạn tại các khu vực và quốc gia khác nhau vị thế của thị trường chứng khoán trong nền kinh tế cũng rất khác nhau. Cộng đồng kinh tế ASEAN (AEC) đã được thành lập vào ngày 31/12/2015. Ngay trước thời điểm thành lập $\mathrm{AEC}$, trong biểu đánh giá $\mathrm{AEC}$ các quốc gia hoàn thành $92,7 \%$ (469/506 biện pháp đã cam kết) so với kế hoạch. Tuy nhiên, mức độ hội nhập tài chính nói chung của ASEAN chỉ đạt 79,5\% chậm hơn so với các lĩnh vực hội nhập khác (biểu đánh giá $\mathrm{AEC}$ ). Mục đích của nghiên cứu này phân tích thực trạng TTCK ASEAN trước thời điểm AEC được thành lập, và xác định xem liệu giá trị vốn hóa TTCK từ năm 2000 đến năm 2014 tại ASEAN6 (gồm Thái Lan, Singapore, Phillipine, Indonesia, Malaysia, và Việt Nam) có ảnh hưởng đến tăng trưởng kinh tế của các quốc gia này hay không. Nếu câu trả lời là có thì giá trị vốn hóa TTCK có ảnh hưởng tích cực hay tiêu cực đến tăng trưởng kinh tế của sáu quốc gia này, ngoài ra, việc phân tích độ lớn của biến đại diện cho quy mô TTCK so với các biến kiểm soát trong mô hình là biến chi tiêu chính phủ và độ mở thương mại cũng rất quan trọng. Dựa trên kết quả nghiên cứu, tác giả sẽ đề xuất một số gợi ý có giá trị đối với các nhà quản lý TTCK nhằm phát huy hiệu quả tăng trưởng nền kinh tế tại sáu quốc gia.

\section{CƠ SỞ LÝ THUYÊT VÀ PHÂN TÍCH KHÁI QUÁT THỊ TRƯờnG CHỨNG KHOÁN ASEAN TRƯỚC THỜI ĐIỂM AEC ĐƯợC THÀNH LẬP}

\subsection{Cơ sở lý thuyết}

Lý thuyết mô hình tăng trưởng của Harrod (1939), Domar (1946) và lý thuyết mô hình tăng trưởng tân cổ điển của Solow (1956) đều thừa nhận vai trò của vốn là tiền đề mở rộng đầu tư, từ đó sẽ tác động đến tăng trưởng kinh tế. Sau này, lý thuyết tăng trưởng nội sinh của Lucas (1988) cũng khẳng định sự phát triển của thị trường tài chính nói chung và TTCK nói riêng, là kênh quan trọng để huy động vốn cho nền kinh tế, ảnh hưởng đến tăng trưởng toàn bộ nền kinh tế. Đã có nhiều nghiên cứu thực nghiệm liên quan đến vai trò của TTCK đối với tăng trưởng kinh tế. Tuy nhiên, kết quả được rút ra từ các nghiên cứu rất khác nhau: trong khi một số nghiên cứu khẳng định sự phát triển của TTCK có ảnh hưởng tích cực đến tăng trưởng kinh tế, ngược lại, cũng có nghiên cứu tìm thấy TTCK có tác động tiêu cực đến tăng trưởng kinh tế, bên cạnh đó, có những nghiên cứu cho thấy chưa đủ cơ sở để nói lên mối liên hệ này.

Demirgue và cộng sự (1996) sử dụng dữ liệu từ 44 nước trong giai đoạn 1986-1993 cho thấy quy mô thị trường chứng khoán có mối tương quan chặt chẽ đến các chỉ số liên quan đến mức độ hoạt động của hệ thống tài chính, ngân hàng, các tổ chức phi ngân hàng cũng như lĩnh vực bảo hiểm, các công ty và quỹ hưu trí khác nhau. Các tác giả kết luận rằng các quốc gia có TTCK phát triển tốt, thường cũng là quốc gia có trung gian tài chính phát triển tốt. Hơn nữa, Demiurgic và cộng sự (1998) đã chỉ ra và tái khẳng định vai trò bồ sung vốn của thị trường chứng khoán song song với hệ thống ngân hàng. Demiurgic và cộng sự (1998) cho rằng TTCK và hệ thống ngân hàng không phải là đối thủ hoặc thay thế nhau trong nền kinh tế. Kết luận này được tìm thấy trong 30 quốc gia từ năm 1980 đến năm 1991.

Kolapo và cộng sự (2012) nghiên cứu tác động của TTCK đến tăng trưởng kinh tế tại Nigeria từ năm 1990-2010. Kết quả nghiên cứu cho thấy TTCK và tăng trưởng kinh tế tại Nigeria có mối quan hệ dài hạn. Ngoài ra, các biến đại diện cho mức độ phát triển của thị trường chứng khoán như: giá trị vốn hóa thị trường, tổng số lượng cổ phiếu mới phát hành, giá trị giao dịch, tổng số lượng chứng khoán niêm yết và chứng khoán chính phủ niêm yết, đều tác động tích cực đến tăng trưởng kinh tể của Nigeria.

Mian và cộng sự (2010) nghiên cứu về mối liên hệ giữa sự phát triển thị trường chứng khoán và tăng trưởng kinh tế tại Pakistan cho giai đoạn 1986-2008. Kết quả nghiên cứu của Mian và cộng sự (2010) cho thấy sự phát triển về quy mô và giá trị vốn hóa của thị trường chứng khoán có ảnh hưởng tích cực đến tăng trưởng kinh tế tại Pakistan trong giai đoạn nghiên cứu.

Agarwal (2001) nghiên cứu mối tương quan giữa một số biến thị trường chứng khoán và đầu tư nhằm đánh giá mối quan hệ giữa tăng trưởng kinh tế và TTCK. Kết quả nghiên cứu tại chín quốc gia Châu Phi từ năm 1992 -1997 cho thấy sự phát triển của thị trường chứng khoán có tương quan với đầu tư và với tốc độ tăng trưởng kinh tế.

Kết quả nghiên cứu Atje và Jovanovic (1993) về thị trường cổ phiếu của 40 quốc gia từ năm 19801988 cho thấy có sự tương quan đáng kể giữa tăng trưởng kinh tế trung bình và vốn hóa thị trường chứng khoán. 
Nyong (1997) đã phát triển một chỉ số tổng hợp đo lường mức độ phát triển thị trường vốn và sử dụng nó để xác định mối quan hệ của nó với tốc độ tăng trưởng kinh tế dài hạn tại Nigeria. Nyong (1997) sử dụng một dữ liệu chuỗi thời gian từ năm 1970 đến năm 1994. Bốn chỉ tiêu đo lường sự phát triển thị trường vốn gồm: tỷ lệ vốn hóa thị trường trên GDP, tỷ lệ của tổng giá trị giao dịch trên sở giao dịch chứng khoán chia cho GDP, giá trị giao dịch của vốn cổ phần chia cho GDP, và số lượng cổ phiếu niêm yết trên GDP. Kết quả tìm thây sự phát triển thị trường vốn ảnh hưởng tiêu cực và có tương quan đáng kể tới sự tăng trưởng dài hạn tại Nigeria.

Henry (2000) tìm thấy một mối quan hệ giữa tăng trưởng kinh tế và các hoạt động thị trường chứng khoán trên thị trường thứ cấp mạnh hơn so với sự luân chuyển vốn giữa các quỹ trên thị trường sơ cấp. Ewah và cộng sự (2009) đánh giá ảnh hưởng hiệu quả của thị trường vốn đến tăng trưởng kinh tế của Nigeria sử dụng dữ liệu chuỗi thời gian từ năm 1961 đến 2004. Ewah và cộng sự (2009) cho thấy rằng thị trường vốn ở Nigeria có tiềm năng hỗ trợ tăng trưởng nhưng nó không đóng góp trực tiếp vào sự tăng trưởng kinh tế Nigeria vì giá trị vốn hóa và vốn hấp thụ của thị trường còn thấp, thiếu tính thanh khoản. Harris (1997) không tìm thấy bằng chứng rằng hoạt động của thị trường chứng khoán có ảnh hưởng đến mức độ tăng trưởng kinh tế

Nghiên cứu của Yartey và cộng sự (2007) sử dụng dữ liệu bảng không cân bằng (unbalanced panel) cho 14 quốc gia ở Châu Phi, kết quả nghiên cứu cho thấy TTCK góp phần hỗ trợ quan trọng cho sự tăng trưởng của các tập đoàn lớn tại các quốc gia này. Tuy nhiên, nghiên cứu cũng chỉ ra được mức vốn hóa và tính thanh khoản của thị trường thấp là những rào cản cho các quốc gia ở Châu Phi khi hội nhập TTCK.

Levine và Zervos (1998) đã sử dụng hồi quy Pool OLS cho dữ liệu bảng gồm 47 quốc gia từ năm 1976-1993 để đánh giá xem liệu thanh khoản thị trường chứng khoán có liên quan đến tăng trưởng, tích lũy vốn và năng suất hay không. Kết quả thực nghiệm cho thấy tính thanh khoản trên thị trường chứng khoán có liên quan chặt chẽ tới sự phát triển, tích lũy vốn và năng suất trong nền kinh tế, trong khi đó, quy mô thị trường chứng khoán không liên quan đến tăng trưởng kinh tế.

\subsection{Phân tích khái quát thị trường chứng khoán ASEAN trong thời gian qua}

Mức độ phát triển của các quốc gia thành viên trong Asean chưa đồng đều

Thị trường chứng khoán ASEAN (TTCK ASEAN) gồm sở GDCK của 6 quốc gia (Thái Lan, Singapore, Phillipine, Indonesia, Malaysia, và Việt Nam) có TTCK phát triển nhất trong 10 quốc gia trong khối. Theo xếp hạng của FTSE từ 2013 đến nay, trong khối ASEAN, chỉ duy nhất Singapore được xếp vào nhóm nước có thị trường vốn phát triển; Thái Lan và Malaixia là thị trường vốn mới nổi phát triển; thị trường vốn của Indonexia và Phillippine thuộc nhóm mới nổi chưa hoàn toàn phát triển; Việt Nam là thị trường cận biên (FTSE Russell, 2015). Có thể thấy, cho đến nay mức độ phát triển của các thành viên trong ASEAN6 hiện nay cũng rất khác biệt, chính vì vậy lộ trình hội nhập thị trường tài chính ASEAN được thực hiện theo công thức "ASEAN -X". Theo công thức này, các thành viên đã sẵn sàng có thể hội nhập ngay, trong khi từng thành viên còn lại sẽ cam kết và đưa ra kế hoạch hội nhập của mình. Như vậy, sự hợp tác TTCK Asean sẽ giúp cơ quan quản lý các quốc gia có mức độ phát triển thấp hơn sẽ được sẻ kinh nghiệm từ các quốc phát triển hơn trong quá trình hội nhập; các nhà đầu tư có thể giao dịch xuyên biên giới với những chứng khoán đang niêm yết tại các Sở giao dịch của các quốc gia thành viên; các tổ chức phát hành có cơ hội huy động vốn tại các nước thành viên; các quỹ đầu tư có khả năng thu hút vốn từ các nhà đầu tư cá nhân trong khu vực.

\section{TTCK của Thái Lan, Singapore, Malaysia tạo tiền đề cho sụ' phát triển TTCK trong khu vục.}

Thái Lan, Singapore, Malaysia là ba quốc gia mà TTCK được thành lập sớm nhất trong ASEAN: Singapore (1960); Thái Lan (1974), Malaysia (1976), và cũng đây cũng là những quốc gia có TTCK phát triển nhất khu vực ASEAN với nhiều sản phẩm dịch vụ đa dạng. TTCK phái sinh (thể hiện cấp độ phát triển cao nhất của TTCK) của Singapore chính thức đi vào hoạt động từ năm 2000. Ngay từ khi hoạt động TTCK phái sinh Singapore đã kết nối liên thông với TTCK Chicago, nơi TTCK phái sinh có lịch sử lâu đời và phát triển nhất trên thế giới, và đến năm 2004 nước này đã đưa quyền chọn cổ phiếu vào giao dịch. So với Singapore, TTCK phái sinh của Thái Lan và Malaysia được ra đời muộn hơn. Hợp đồng tương lai chỉ số chứng khoán bắt đầu được phép giao dịch tại TTCK Malaysia từ năm 2004, Thái Lan năm 2006; quyền chọn chỉ số của Thái Lan được chính giao dịch vào năm 2007. Bên cạnh đó, nhằm tăng sức cạnh tranh và mức độ hội nhập của các CTCK nội địa, cả Thái Lan, Singapore, Malaysia đều cho phép thành lập công ty chứng khoán $100 \%$ vốn nước ngoài từ trước năm 2005 . 


\section{Kết quả thục hiện các sáng kiến hội nhập TTCK ASEAN đến cuối năm 2015}

Với mục đích thúc đẩy hội nhập các thị trường vốn trong khu vực đạt được các mục tiêu của $\mathrm{AEC}$ 2015, diễn đàn thị trường vốn ASEAN (ACMF) được thành lập vào tháng 4/2004 để những người đứng đầu cơ quan quản lý chứng khoán của các nước ASEAN trao đồi. Trong quá trình thực hiện các sáng kiến của ACMF, mức độ hội nhập TTCK ASEAN đến cuối năm 2015 đã đem lại nhiều kết quả khả quan khi đã thống nhất được cơ sở cho việc liên kết giao dịch, niêm yết, phát hành và liên kết đầu tư xuyên biên giới (Satoshi, 2014). Cụ thể:

Liên quan đến niêm yết và phát hành

(A) Khung rà soát thuận lợi cho việc Niêm yết thêm: là cơ chế được thiết kế để giảm chi phí và nâng cao hiệu quả niêm yết trên thị trường thứ cấp của các tập đoàn trong khu vực trên các Sở giao dịch chứng khoán ASEAN bằng việc đơn giản hóa thủ tục đánh giá.

(B) Thẻ điểm Quản trị công ty ASEAN: Được sử dụng để đánh giá quản trị công ty của các công ty niêm yết (CTNY) trong khu vực ASEAN

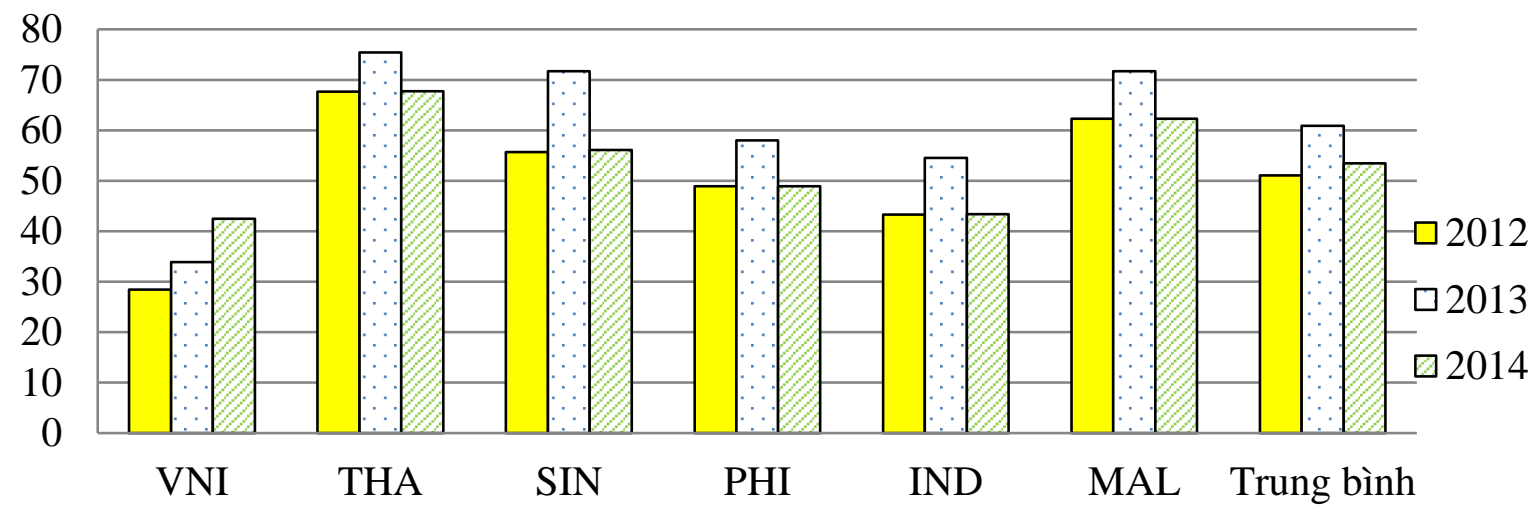

Nguồn: http://www.ASEANcorpgov.com

Hình 1: Điểm quản trị doanh nghiệp trung bình của các doanh nghiệp niêm yết trong ASEAN6

Thẻ điểm Quản trị công ty được kỳ vọng nâng cao hình ảnh CTNY, khả năng thu hút đầu tư cũng như nâng cao hình ảnh thị trường vốn của khu vực ASEAN. Trong lễ vinh danh các CTNY tốt nhất ASEAN 2015, công ty của Malaysia đứng đầu nhóm 5 CTNY tốt nhất; Singapore có 2 đại diện xếp thứ 2 và thứ 5 ; Thái Lan có 2 công ty đứng thứ 3 và thứ 4 . Khi mở rộng Top 50 doanh nghiệp tốt nhất ASEAN: Thái Lan (23); Philippines (11); Singapore (8); Malaysia (6) và Indonesia (2).

Giai đoạn 2012-2014, ASEAN3 có điểm quản trị công ty trung bình của các CTNY cao hơn mức trung bình. Đây cũng là nhóm ba quốc gia dẫn dắt TTCK ASEAN khi SGDCK của họ đã kết nối điện tử, giao dịch liên thông với nhau từ tháng $9 / 2012$. Điều thú vị ở đây là trong cả 03 năm, điểm quản trị công ty trung bình của các CTNY trên TTCK Singapore (thuộc nhóm nước phát triển) thấp hơn so với Thái Lan và Malaysia (được xếp vào nhóm nước mới nổi). Đây là một trong những minh chứng cho sự hội nhập mạnh mẽ của TTCK Thái Lan và Malaysia trong thời gian qua. Ba quốc gia có điểm quản trị công ty thấp hơn mức trung bình trong khu vực là Phillippine, Indonesia và Việt Nam. Trong đó, TTCK Việt Nam được đánh giá là non trẻ nhất so với 5 TTCK còn lại, tuy nhiên, những nỗ lực hội nhập TTCK của Việt Nam đã được ghi nhận khi điểm quản trị công ty của Việt Nam tăng đều qua các năm. Như vậy, nếu dựa trên thẻ điểm quản trị công ty trong ASEAN có thể thấy sự hội nhập TTCK Thái Lan đang dẫn đầu, nỗ lực cùng với Singapore trở thành TTCK dẫn dắt TTCK ASEAN.

(C) Thống nhất chuẩn mực công bố thông tin của ASEAN và các tiêu chuẩn bổ sung: được phát triển để nâng cao hiệu quả của các vấn đề phát hành chứng khoán xuyên biên giới.

Co sở cho liên kết giao dịch

(D) Liên quan đến Sở giao dịch chứng khoán ASEAN: cho phép cập nhật thông tin của 180 chứng khoán thông qua một mạng lưới điện tử liên kết bảy sở giao dịch trong ASEAN (Indonesia, Malaysia, 
Philippines, Singapore, Thái Lan, Hà Nội, Hồ Chí Minh) theo ngày. Đây là những cổ phiếu có giá trị giao dịch lớn, vốn hóa cao, thanh khoản tốt, đóng vai trò quảng bá TTCK mỗi nước đến các nhà đầu tư quốc tế.

Việc thiết lập cấu trúc này được nghiên cứu theo phân nhóm công tác chịu trách nhiệm về bốn lĩnh vực: lập kế hoạch kinh doanh, quy định pháp lý, quản lý thị trường và công nghệ.

(E) Công nhận trình độ chuyên môn lẫn nhau về bằng cấp, đào tạo và kinh nghiệm của các chuyên gia thị trường.

Liên quan đến đầu tư

(F) Khung khổ pháp lý cho phép Chào bán xuyên biên giới đối với các Quỹ đầu tu tập thể trong $\operatorname{ASEAN}(C I S)$, còn gọi là hệ thống Quỹ hộ chiếu Châu Á - "fund passport"

(G) Phát triển chi số chúng khoán của ASEAN:

Bảng 1: Thống kê một số chỉ số chứng khoán trong khu vực ASEAN

\begin{tabular}{|l|l|c|}
\hline \multicolumn{1}{|c|}{ Chỉ số } & \multicolumn{1}{|c|}{ Đặc điểm } & Năm công bố \\
\hline FTSE ASEAN All-Share & $\begin{array}{l}\text { Tổng hợp đại diện cho 90-95\% giá trị vốn hóa thị trường của các } \\
\text { cổ phiếu niêm yết tại các Sở GDCK trong khu vực }\end{array}$ & 2005 \\
\hline FTSE/ASEAN40 & 40 công ty lớn nhất niêm yết trên thị trường ASEAN & 2005 \\
\hline FTSE ASEAN Stars & $\begin{array}{l}30 \text { công ty lớn nhất về vốn hóa và tính thanh khoản của mỗi quốc } \\
\text { gia trong ASEAN }\end{array}$ & 2014 \\
\hline $\begin{array}{l}\text { FTSE ASEAN All-Share } \\
\text { Ex-Developed Index }\end{array}$ & $\begin{array}{l}\text { gồm cố phiếu của các nước, không kể cổ phiếu của nước đã phát } \\
\text { triển }\end{array}$ & 2014 \\
\hline
\end{tabular}

Nguồn: http://ASEANexchanges.com/

(Đơn vị: \% nội khối so với tổng số)

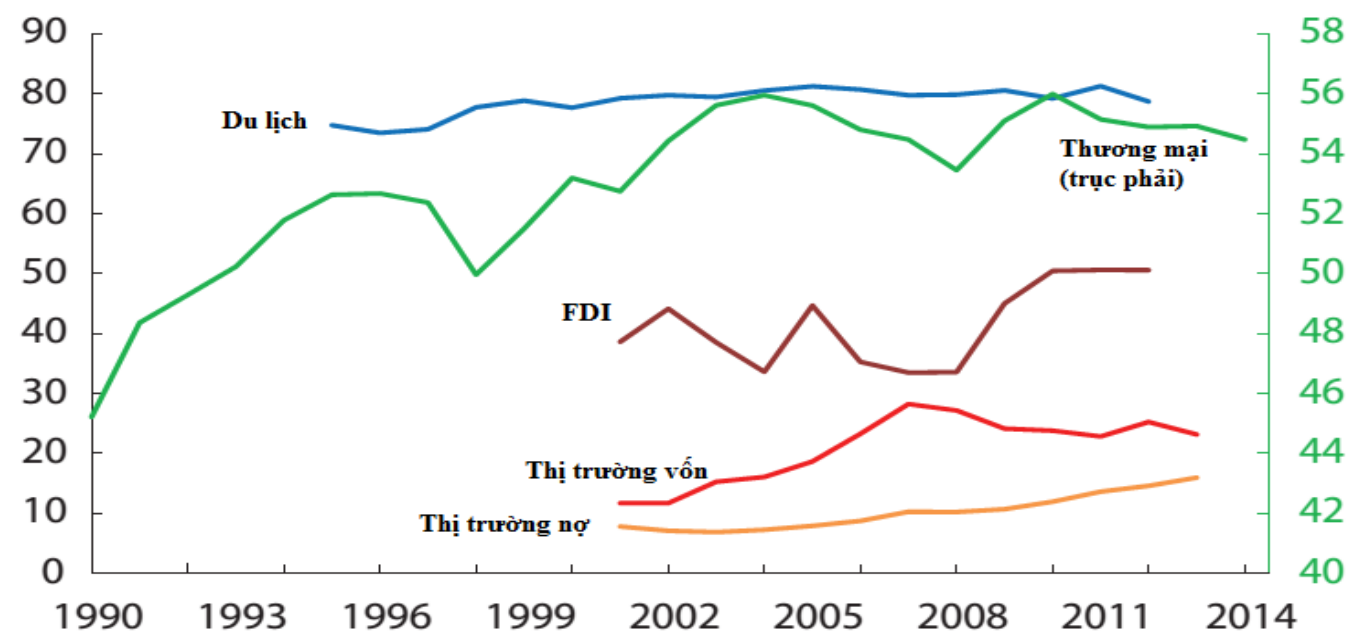

Ghi chú: FDI là vốn đầu tư trục tiếp nước ngoài

Nguồn: Ngân hàng phát triển Châu Á-ADB tính toán và tổng hợp tù tổng thu ký ASEAN, Quỹ tiền tệ quốc tế-IMF, Tổ chức hợp tác và phát triển kinh tế-OECD.

Hình 2: Thống kê các chỉ số hội nhập theo lĩnh vực ở Châu Á

Đến cuối 2015, ASEAN đã hoàn thành khoảng 90\% công việc theo lộ trình xây dựng cộng đồng $\mathrm{AEC}$, trong đó hội nhập tài chính nói chung và hội nhập TTCK ASEAN nói riêng đang bị đánh giá là chậm hơn so với hội nhập thương mại. Một số chỉ tiêu liên quan đến lĩnh vực chứng khoán vẫn chưa đạt được so với kế hoạch như: (i) Tự do hóa dòng vốn gián tiếp đã được thực hiện đầy đủ theo cam kết ở tẩt cả các quốc gia trong ASEAN ngoại trừ Myanmar. Trong đó, Indonesia và Việt Nam là hai quốc gia có tỷ lệ tự do hóa dòng vốn dưới $80 \%$, thấp nhất 10 quốc gia trong ASEAN (Deloitte, 2015). (ii) Đến nay chỉ 
có ASEAN5 thực hiện tự do hóa dịch vụ môi giới và sản phẩm tài chính, còn xét trong cả khu vực thì chỉ tiêu này mới đang ở giai đoạn chấp nhận về mặt nguyên tắc giữa các thành viên. (iii) Các thành viên vẫn chưa thống nhất tiêu chuẩn quy định về chứng khoán nợ. (iv) Công bố thông tin và quy tắc phân bổ...vẫn đang trong tiến trình thực hiện.

Ở phần tiếp theo, tác giả sẽ xác định xem liệu giá trị vốn hóa TTCK từ năm 2000 đến năm 2014 tại ASEAN6 có ảnh hưởng đển tăng trưởng kinh tế của các quốc gia này hay không. Nếu có ảnh hưởng thì chiều ảnh hưởng là tích cực hay tiêu cực đến tăng trưởng kinh tế. Bên cạnh đó, độ lớn của mức độ ảnh hưởng của biến đại diện cho quy mô TTCK so với các biển kiểm soát trong mô hình sẽ như thế nào, từ đó tác giả sẽ đề xuất một số gợi ý cho các nhà quản lý TTCK.

\section{DŨ̉ LIỆU VÀ PHƯƠNG PHÁP NGHIÊN CỨU}

\subsection{Dũ̃ liệu nghiên cứu}

Dữ liệu nghiên cứu được thu thập từ bộ dữ liệu thống kê của Ngân hàng thế giới (Worldbank) của sáu quốc gia trong ASEAN gồm Việt Nam, Thái Lan, Singapore, Phillipine, Indonesia, Malaysia trong giai đoạn từ năm 2000 đến 2014. Thông qua lược khảo các nghiên cứu trước đây ở phần cơ sở lý thuyết, nghiên cứu này đã lựa chọn và sử dụng các biến sau trong mô hình thực nghiệm.

Trong đó: i: Quốc gia thứ i (i=1-6); t: năm (từ 2000-2014)

Bảng 2: Mã biến, tên biến và cách đo lường các biến trong mô hình

\begin{tabular}{|c|c|c|c|}
\hline Mã biến & Tên biến & Đo lường biến & Các nghiên cứu trước \\
\hline Biến phụ thuộc & & & \\
\hline GDP & $\begin{array}{c}\text { Tăng trưởng kinh } \\
\text { tế }\end{array}$ & $\begin{array}{l}\text { Tốc độ tăng trưởng tổng sản phẩm quốc } \\
\text { nội hàng năm }(\%) \text { theo mức giá thị } \\
\text { trường với năm gốc là } 2005 \text {. }\end{array}$ & $\begin{array}{l}\text { Demirgue và cộng sự (1996), } \\
\text { Kolapo và cộng sự (2012), Barro } \\
\text { (1991), Easterly và cộng sự } \\
\text { (1993), Gylfason }(1999) \text {, Sharma } \\
\text { và Panagiotidis }(2005), . .\end{array}$ \\
\hline
\end{tabular}

Biến độc lập

Quy mô vốn hóa $\quad \%$ giá trị vốn hóa của các công ty niêm của thị trường yết so với tổng sản phẩm quốc nội tính chứng khoán theo đồng nội tệ = (thị giá cổ phiếu cuối năm nhân với $(\mathrm{x})$ Số lượng cổ phiếu đang lưu hành của các công ty niêm yết cuối năm) chia cho (/) tổng sản phẩm quốc nội tính theo đồng nội tệ

Demirgue và cộng sự (1996), Kolapo và cộng sự (2012), Mian và cộng sự (2010), Agarwal (2001), Nyong (1997), Henry (2000), Ewah và cộng sự (2009), Harris (1997), Yartey và cộng sự (2007), Levine và Zervos (1998)

Chi tiêu chính phủ

GOV

Độ mở thương mại

OPEN
Tốc độ tăng chi tiêu chính phủ hàng năm (\%) với năm gốc là 2005, gồm các khoản chi thường xuyên của chính phủ (hàng hóa, dịch vụ, lương nhân viên), các khoản chi về quốc phòng và an ninh quốc gia, chưa bao gồm chi phí cho quân sự.

\% tổng kim ngạch xuất nhập khẩu hàng hóa và dịch vụ so với tổng sản phẩm quốc nội hàng năm
Barro (1991), Easterly và cộng sự (1993), Grier và cộng sự (1989),

Gylfason (1999), Sharma và Panagiotidis (2005), Al-Yousif (1997), Ekanayake (1999), Ibrahim (2002), 


\subsection{Phương pháp nghiên cứu}

Một số nghiên cứu trước như Barro (1991), Griffin (1998), Levine \& Zervos (1998) đều ủng hộ luận điểm không có hiện tượng nội sinh giữa của biến tăng trưởng kinh tế với các biến quy mô vốn hóa TTCK, biến độ mở thương mại, và biến chi tiêu chính phủ trong mô hình. Ngoài ra, mô hình trong bài viết này không sử dụng biến trễ của biến phụ thuộc như là một biển độc lập trong mô hình. Do đó, tác giả cho rằng việc sử dụng mô hình cùng các kiểm định mô hình trong bài là phù hợp với dữ liệu nghiên cứu. Để kiểm định giả thuyết "Quy mô vốn hóa của thị trường chứng khoán không ảnh hưởng đến tăng trưởng kinh tế tại các quốc gia ASEAN6", ban đầu nghiên cứu này sử dụng các phương pháp hồi quy trên dữ liệu bảng (panel data), gồm: hồi quy tuyến tính theo phương pháp bình phương nhỏ nhất tổng quát (Pool Regression: POLS); mô hình hồi quy ảnh hưởng cố định (Fixed effects model: FEM) và mô hình hồi quy ảnh hưởng ngẫu nhiên (Random effects model: REM). Để lựa chọn phương pháp hồi quy nào là phù hợp nhất trong ba phương pháp trên, các kiểm định được sử dụng là: kiểm định $\mathrm{F}$ test; kiểm định Lagrange Multiplier (LM test, Breush và Pagan, 1980) và kiểm định Hausman (Hausman, 1978). Kiểm định F-test để chọn lựa giữa mô hình POLS và mô hình FEM. Kiểm định LM test để biết được nên chọn mô hình POLS hay mô hình REM. Để lựa chọn giữa mô hình FEM và REM, sử dụng kiểm định Hausman.

Sau khi lựa chọn được mô hình phù hợp, nghiên cứu này sẽ tiếp tục tiển hành các kiểm định phương sai thay đổi và tương quan chuỗi của mô hình. Nếu mô hình bị phương sai thay đổi và/hoặc bị tương quan chuỗi thì sẽ được khắc phục những vi phạm này bằng phương pháp bình phương nhỏ nhất tổng quát (GLS).

\section{KẾT QUẢ VÀ THẢO LUẬn KẾT QUẢ}

\subsection{Thống kê mô tả}

Bảng 3: Kết quả thống kê mô tả

\begin{tabular}{|lrrrrr|}
\hline \multicolumn{1}{|c}{ Ký hiệu biến } & \multicolumn{1}{c}{ Biến } & \multicolumn{1}{c}{ Trung bình } & \multicolumn{1}{c|}{ Độ lệch chuẩn } & \multicolumn{1}{c|}{ Giá trị nhỏ nhất } & \multicolumn{1}{c|}{ Giá trị lớn nhất } \\
\hline GDP & 90 & 5,286646 & 2,477849 & $-1,513685$ & 15,24038 \\
STOCK & 90 & 86,00746 & 73,49911 & 0,1246637 & 299,5737 \\
GOV & 90 & 6,039494 & 4,273002 & $-3,971871$ & 20,86291 \\
OPEN & 90 & 10,64322 & 12,73593 & $-19,37027$ & 43,59749 \\
\hline
\end{tabular}

Nguồn: Theo tính toán của tác giả

Kết quả từ Bảng 3 cho thấy, trong các quốc gia nghiên cứu, Singapore là quốc gia đứng đầu tốc độ tăng trưởng vào năm 2010 , mức vốn hóa của thị trường chứng khoán cao nhất vào năm 2007 , tốc độ tăng chi tiêu Chính phủ hàng năm đạt đỉnh vào năm 2000. Ngược lại, tốc độ tăng trưởng giảm mạnh nhất thuộc về Malaysia vào năm 2009 , mức vốn hóa của thị trường chứng khoán thấp nhất là thời điểm Việt Nam bắt đầu thực hiện giao dịch cổ phiếu từ năm 2000, Phillipine có tốc độ tăng chi tiêu Chính phủ hàng năm thấp nhất vào năm 2002. Độ mở thương mại của Indonesia có tốc độ đạt cao nhất vào năm 2010 , giá trị thấp nhất thuộc về Malaysia năm 2009

Bảng 4: Ma trận hệ số tương quan giữa các biến và kiểm định VIF

\begin{tabular}{lllll|lrr}
\hline \multicolumn{3}{c}{ Ma trận tương quan giữa các biến } & \multicolumn{3}{c}{ Kiểm định VIF } \\
\hline GDP & \multicolumn{1}{c}{ GDP } & STOCK & GOV & OPEN & \multicolumn{1}{c}{ Biến } & VIF & 1/VIF \\
STOCK & 1,0000 & & & STOCK & 1,01 & 0,985446 \\
GOV & $0,0982^{* *}$ & 1,0000 & & OPEN & 1,01 & 0,987854 \\
OPEN & $0,1337^{*}$ & $-0,0496^{*}$ & 1,0000 & & GOV & 1,00 & 0,997422 \\
\hline
\end{tabular}

(Ghi chú: ***, **, * úng với các múc ý nghĩa thống kê 1\%, 5\%, 10\%) Nguồn: Theo tính toán của tác giả

Kết quả từ Bảng 4 cho thấy hiện tượng đa cộng tuyến giữa các biến trong mô hình được đánh giá là không nghiêm trọng bởi hai lý do. Thứ nhất, hệ số tương quan giữa các cặp biến đều không vượt quá $(0,62)$. Thứ hai, hệ số phóng đại phương sai (VIF) của tất các biến độc lập và VIF trung bình (là 1,01$)$ trong mô hình đều khá nhỏ (dưới 10). 
Hệ số tương quan giữa mức vốn hóa TTCK với hai biến chi tiêu của Chính phủ và độ mở của nền kinh tế đều là âm thể hiện hai cặp biến là tương quan nghịch biến; mức độ phụ thuộc giữa các biến này yếu do giá trị tương quan nhỏ. Các biến cặp biến còn lại đều có tương quan đồng biến.

\subsection{Kiểm định mô hình và thảo luận kết quả nghiên cứu}

Thông qua các kiểm định cho thấy mô hình POLS (Pool OLS) là phù hợp nhất trong ba mô hình đã xét, mô hình này không bị tương quan chuỗi (kiểm định Wooldridge), mà chỉ bị phương sai thay đổi (kiểm định $\mathrm{LM}$ ). Do đó, để khắc phục những vi phạm này, nghiên cứu sẽ sử dụng phương pháp GLS để khắc phục phương sai thay đổi. Bảng 5 , tác giả trình bày kết quả hồi quy mối quan hệ giữa tăng trưởng kinh tế tại ASEAN6 và các yếu tố theo các phương pháp ước lượng.

Bảng 5: Kết quả mô hình hồi quy theo các phương pháp ước lượng

\begin{tabular}{|c|c|c|c|c|}
\hline Biến & POLS & FEM & REM & GLS \\
\hline STOCK & $0,00592068 * *$ & 0,00361809 & $0,00569234 * *$ & $0,00666938 * * *$ \\
\hline GOV & $0,08450273 *$ & $0,09751045^{*}$ & $0,08530307 *$ & $0,06824763 *$ \\
\hline OPEN & $0,12452028 * * *$ & $0,08887579 *$ & $0,12340336 * * *$ & $0,12067632 * * *$ \\
\hline Hằng số & $2,9417734 * * *$ & $3,4406249 * * *$ & $2,9684656 * * *$ & $3,2267978 * * *$ \\
\hline $\mathrm{N}$ & 90 & 90 & 90 & 90 \\
\hline $\mathrm{R}^{2}$ & 0,43354868 & 0,14741101 & & 0,43204329 \\
\hline Mức ý nghĩa & & $* \mathrm{p}<0,08$ & $* * \mathrm{p}<0,05$ & $* * * \mathrm{p}<0,001$ \\
\hline $\begin{array}{l}\text { F test } \\
\text { LM test } \\
\text { Hausman test }\end{array}$ & & $\begin{array}{l}\mathrm{F}(14,72)=1,28 \\
\text { chibar2(01) }=0,09 \\
\text { chi2 }(4)=5,46\end{array}$ & $\begin{array}{l}\text { Prob }>F \\
\text { Prob }>c \\
\text { Prob }>\text { ch }\end{array}$ & $\begin{array}{l}=0,2427 \\
\text { libar2 }=0,3804 \\
2=0,1410\end{array}$ \\
\hline
\end{tabular}

Nguồn: Theo tính toán của tác giả

Hàm hồi quy từ mô hình GLS có dạng:

GDP $=3,2267978+0,00666938 \times S T O C K+0,06824763 \times$ xGOV + 0,12067632xOPEN

Hệ số của tất cả các biến trong mô hình đều dương thể hiện các biến đều tác động tích cực đến tăng trưởng kinh tế của các quốc gia nghiên cứu. Trong đó, biến độ mở thương mại có ả̉nh hưởng mạnh nhất đến tăng trưởng kinh tế, điều này phù hợp trong thực tế khi thương mại là lĩnh vực được đánh giá có mức độ hội nhập sâu thứ nhì trong các lĩnh vực (chỉ sau du lịch, Hình 2) mà các quốc gia trong ASEAN cam kết. Khi tỷ trọng tổng kim ngạch xuất nhập khẩu hàng hóa và dịch vụ so với GDP tăng thêm $1 \%$ sẽ thúc đẩy kinh tế tăng trường thêm $0,121 \%$.

Chi tiêu chính phủ có tác động tích cực đến tăng trưởng kinh tế tại các nước ASEAN6. Kết quả này phù hợp với kết luận từ các nghiên cứu của Barro (1991), Lin và Liu (2000), Zhang và Zhou (1997). Trong điều kiện các yếu tố khác không thay đổi, khi chi tiêu chính phủ tăng thêm $1 \%$ thì tổng sản phẩm quốc nội sẽ tăng thêm $0,068 \%$.

Tỷ trọng vốn hóa TTCK: Trong ba biến nghiên cứu, hệ số của biến tỷ trọng vốn hóa TTCK có mức ảnh hưởng thấp nhất đến tăng trưởng kinh tế. Kết quả này hợp lý vì lĩnh vực hội nhập tài chính là lĩnh vực chỉ đạt $79,5 \%$ so với kế hoạch, thấp hơn mức trung bình theo kế hoạch của tất cả các chỉ tiêu hội nhập là $92,7 \%$. Tuy nhiên, biến tỷ trọng vốn hóa TTCK vẫn đảm bảo có ý nghĩa thống kê cao trong mô hình. Với mức ý nghĩa $1 \%$, tỷ trọng vốn hóa TTCK có ảnh hưởng tích cực đến tăng trưởng kinh tế tại các quốc gia nghiên cứu. Nếu tỷ trọng vốn hóa TTCK so với GDP tăng thêm $1 \%$ sẽ tạo lực đẩy để giá trị tổng sản phẩm quốc nội tăng thềm $0,007 \%$.

\section{KẾT LUẬN}

Kết quả nghiên cứu sáu quốc gia trong ASEAN gồm Việt Nam, Thái Lan, Singapore, Phillipine, Indonesia, Malaysia trong giai đoạn từ năm 2000 đến 2014 khẳng định giá trị vốn hóa TTCK có tác động đến tăng trưởng kinh tế tại các quốc gia này, hướng của tác động là tích cực. Dựa trên kết quả nghiên cứu, tác giả đưa ra một số gợi ý cho các nhà quản lý và thiết lập chính sách nhằm phát triển TTCK bền vững từ đó tạo động lực cho tăng trưởng kinh tế tại các quốc gia trong ASEAN6: 
Thứ nhất, để thu hẹp khoảng cách về trình độ phát triển giữa các TTCK trong ASEAN, các nước có mức độ phát triển thấp hơn nên ưu tiên tăng cường các hệ thống hỗ trợ công nghệ tài chính. Ngoài ra, những nước này có thể xem xét hội nhập dần dần thông qua các giao dịch xuyên biên giới trước hơn là chỉ tập trung phát triển TTCK trong nước.

Thứ hai, nhằm tăng quy mô của TTCK, từng quốc gia đặc biệt là các quốc gia có trình độ phát triển thấp hơn cần tăng số lượng các công ty niêm yết (tăng nguồn cung đối với TTCK), đảm bảo tính thanh khoản với chi phí thấp, đa dạng các sản phẩm tài chính để thu hút thêm nhiều các tổ chức đầu tư vào TTCK (tăng nguồn cầu cho TTCK).

Thứ ba, bộ ba Singapore, Thái Lan, Malaysia đang dẫn đầu trong trong tiến trình hội nhập TTCK ASEAN trong thời gian qua. Tiến trình hội nhập suôn sẻ của ba quốc gia này thể hiện đây là một mô hình thành công trong hội nhập TTCK để các thành viên còn lại có thể học hỏi. Ba quốc gia là Phillipine, Indonesia, và Việt Nam cần sớm hiện thực một số vấn đề nhằm thu hút được nguồn vốn nước ngoài đầu tư gián tiếp vào TTCK. Chẳng hạn ba quốc gia này cần đơn giản thủ tục hành chính trong các thủ tục liên quan đến việc cấp mã số giao dịch chứng khoán của các nhà đầu tư nước ngoài để những nhà đầu tư này có thể tận được những cơ hội đầu tư trên TTCK trong cả ngắn và dài hạn. Bên cạnh đó, Phillipine, Indonesia, và Việt Nam có thể xem xét tăng tỷ lệ sở hữu của các nhà đầu tư nước ngoài đối với các doanh nghiệp trong nước trong nhiều lĩnh vực hơn và việc hiện thực hóa tiến trình này diễn ra nhanh chóng hơn. Ngoài ra, muốn thu hút thêm được nguồn vốn gián tiếp thì Phillipine, Indonesia, và Việt Nam cần cởi mở hơn đối với vấn đề tự do các dòng vốn gián tiếp nhằm gia tăng được nguồn vốn nước ngoài đầu tư vào TTCK.

\section{TÀI LIỆU THAM KHẢO}

[1] Al-Yousif, Y. K. (1997), "Exports and Economic Growth; Some Empirical Evidence from the Arab Gulf countries", Applied Economics, 693-697.

[2] Atje, R. \& Jovanovic (1993). Stock Market and Development. European Economic Review, 37: 632-640.

[3] Agarwal, S. (2001). Stock Market Growth and Economic Growth: Preliminary Evidence from African Countries. Journal of Sustainable Development in Africa (JSDA). www.jsd-africa.com.

[4] Bahl, R. W.,\& Linn, J. F (1992). Urban public finance in developing countries. New York: Oxford Univ. Press

[5] Barro, R. (1990), "Government spending in a simple model of endogenous growth", Journal of Political Economy 98, 103-25

[6] Barro, R.J., (1991). Economic growth in a cross section of countries. Quarterly Journal of Economics. 106: $407-444$.

[7] Demirgue Kunt A, Levin R 1996. Stock Market Development and Financial Intermediaries: Stylized Facts. The World bank Economic Review, 10(2): 241-265.

[8] Demirgue Kunt A Asli, Levin R 1996. Stock Market, Corporate Finance and Economic Growth: An Overview. The World Bank Review, 10(2): 223-239.

[9] Deloitte (2015). The ABC of AEC: To 2015 and beyond. Deloitte Southeast Asia Ltd. p12.

[10] Domar, Evsey, 1946. Capital Expansion, Rate of Growth, and Employment. Econometrica. 14 ,2: 137-147.

[11] Ewah SOE, Esang AE, Bassey JU (2009). Appraisal of Capital Market Efficiency on Economic Growth in Nigeria. International Journal of Business and Management, December, pp. 219-225.

[12] Harris RDF 1997. Stock Markets and Development: A Re-assessment. European Economic Review, 1: 136139.

[13] Harrod, Roy F., 1939. An Essay in Dynamic Theory. The Economic Journal. 49 ,193: 14-33

[14] Henry PB 2000. Do Stock Market Liberalization cause Investment Booms. Journal of Financial Economics, 58: 301-334. 
[15] Kolapo, F. T.\& Adaramola, A. O. (2012). The Impact of the Nigerian Capital Market on Economic Growth (1990-2010). International Journal of Developing Societies Vol. 1, No. 1, 2012, 11-19.

[16] Easterly, W. and Rebelo, S. (1993), "Fiscal policy and economic growth: an empirical investigation", Journal of Monetary Economics, 32, 417-58.

[17] Ekanayake, EM. (1999), "Exports and Economic Growth in Asian Developing Countries: Cointegration and Error-correction Models", Journal of Economic Development, Vol. 24, No. 2, pp. 43-56.

[18] FTSE Russell (2015). From frontier to developed - the FTSE ASEAN Index Series, FTSE Russell, May 2015.

[19] Grier, K. and G. Tullock, (1989), “An empirical analysis of cross-national economic growth, 1951-1980”, Journal of Monetary Economics 87, 225-252.

[20] Griffin, 1998. Stock Market and Economic Growth: A Positive Long-Run Relation. DESA Working Pape, No.29, ST/ESA/DWP/29.

[21] Gylfason, D. (1999), “Exports, Inflation and Growth”, World Development, Vol. 27, No. 6, pp. 1031-1057.

[22] Ibrahim, I. (2002), “On Exports and Economic Growth”, Journal Pengurusan, Vol. 21, pp. 3-18.

[23] Levine R, Zervos S 1996. Stock Market Development and Long-run Growth. The World Bank Economic Review, 10(3): 323 - 339

[24] Levine R, Zervos S 1998. Stock Market Development and Long-run Growth. American Economic Review, 88(3): 537- 558.

[25] Lucas, R., E., 1988. On the mechanics of economic development. Journal of Monetary Economics, vol. 22, no. 1 , pp. 3-42.

[26] Mian, S. N., Muhammad, M. N. \& Usman, J. G. (2010). Relationship between Economic Growth and Stock Market Development.African Journal of Business Management Vol. 4(16), pp. 3473-3479. Available online at http://www.academicjournals.org/AJBM

[27] Nyong MO 1997. Capital Market Development and Long run Economic Growth: Theory, Evidence and Analysis, First Bank Review, December pp. 13-38.

[28] Patrick, H. T. (1966). Financial development and economic growth in underdeveloped countries. Economic Development and Cultural Change, 14(2): $174-189$.

[29] Sharma, A. \& Panagiotidis, T. (2005), “An Analysis of Exports and Growth in India: Co-integration and Causality Evidence (1971-2001)”, Review of Development Economics, Vol. 9, No. 2, pp. 232-248.

[30] Solow, R. M., 1956. A contribution to the theory of economic growth. The Quarterly Journal of Economics, vol. 70, pp. 65-94.

[31] Yartey, C. A. \& Adjasi, C. K. (2007). Stock Market Development in Sub-Saharan Africa: Critical Issues and Challenges. IMF Working Paper, WP/07/209.

Ngày nhận bài: 15/04/2016

Ngày chấp nhận đăng: 12/04/2017 